\title{
Bencana Kemanusiaan dalam Tinjauan Filsafat Perenial
}

\author{
Abdillah \\ Jurusan Aqidah dan Filsafat, Fakultas Ushuluddin \\ UIN Sunan Gunung Djati Bandung \\ abdillahagung05@uinsgd.ac.id
}

\begin{abstract}
The research objective was to analyze the phenomenon of floods and landslides in the perspective of perennial philosophy. The method used in this research is a type of qualitative research through literature study. The results of this study indicate that in the perspective of perennial philosophy, various disaster phenomena such as floods and landslides are caused by human behavior that has been arbitrary towards nature. Especially, with the development of modern science and technology that has encouraged humans to exploit massively natural resources, thus losing the balance in nature. Excessive exploitation of nature causes nature to be damaged and in the end there are terrible disasters. The conclusion from the research is that various natural disasters such as floods and landslides that occur in the midst of Indonesian human life can be viewed from the perspective of perennial philosophy. This research recommends the importance of preserving nature. Besides that, the importance of reviewing and dismantling modern science has killed perennial metaphysics which shows the essence of divine reality in life and mind.
\end{abstract}

Keywords: Humanitarian disaster; Modern science; Perennial philosophy.

Abstrak
Tujuan penelitian adalah untuk menganalisis tentang
fenomena banjir dan longsor dalam perspektif filsafat
perenial. Metode yang digunakan pada penelitian ini adalah
jenis penelitian kualitatif melalui studi pustaka. Hasil
penelitian ini menunjukan bahwa dalam perspektif filsafat
perennial, berbagai fenomen bencana seperti banjir dan tanah
longsor disebabkan oleh perilaku manusia yang telah
sewenang-wenang terhadap alam. Terutama, dengan
perkembangan sains dan teknologi modern yang telah
mendorong manusia melakukan ekploitasi secara masif


terhadap sumber daya alam hingga hilangnya keseimbangan pada alam. Ekploitasi alam yang berlebihan menyebabkan alam rusak dan pada akhirnya timbul berbagai bencana yang mengerikan. Kesimpulan dari penelitian adalah berbagai fenomen bencana alam seperti banjir dan tanah longsor yang terjadi di tengah-tengah kehidupan manusia Indonesia bisa ditinjau dari sudut pandang filsafat perenial. Penelitian ini merekomendasikan pentingnya menjaga alam. Disamping itu, pentingnya meninjau dan melucuti kembali sains modern yang telah mematikan metafisika perenial yang memperlihatkan suatu hakikat kenyataan Ilahi dalam kehidupan dan pikiran.

Kata kunci: Bencana kemanusiaan; Filsafat perenial; Sains modern.

\section{Pendahuluan}

Hari ini, kehidupan umat manusia dihadapkan pada berbagai bencana alam yang berulang kali terjadi. Bahkan, akhir-akhir ini, bencana banjir dan longsor melanda sejumlah wilayah di Indonesia (Saptoyo, 2021). Badan Nasional Penanggulangan Bencana (BNPB) mencatat ada sekitar 7.574 kali bencana banjir yang terjadi di Indonesia sejak tahun 2011-2020. Meskipun intensitas banjir fluktuatif, namun bencana ini memiliki tingkat intensitas yang cukup sering selama 10 tahun terakhir. Terutama, banjir yang paling banyak terjadi yakni pada 2019 sebanyak 1.271 kali (Cindy Mutia Annur, 2020). Berbagai peristiwa banjir dan longsor tentunya bukan tanpa sebab. Banjir di Kalimantan Selatan misalnya, berdasarkan laporan Wahana Lingkungan Hidup (Walhi) disebabkan karena adanya deforestasi atau tutupan hutan yang berdampak pada hilangnya struktur dan fungsi hutan (Saptoyo, 2021). Bukan tanpa alasan, Walhi mencatat bahwa ada dari jumlah lahan 3,7 hektar, setengahnya dikuasai oleh perusahaan tambang dan sawit. Atas dasar fakta ini, maka bencana banjir di Kalsel adalah akibat dari hilangnya fungsi hutan (Saptoyo, 2021).

Penelitian mengenai bencana yang ditinjau dari berbagai perspektif sudah banyak dilakukan oleh para peneliti sebelumnya. Misalnya penelitian yang dilakukan oleh Fata (2015), “Teologi Lingkungan Hidup dalam Perspektif Islam," artikel ini terbit di jurnal Ulul Albab: Jurnal Studi Islam. Dalam penelitian ini, penulis menyatakan bahwa kerusakan alam diyakini bersumber dari diri manusia, yaitu pola pikir manusia yang menempatkan dirinya sebagai pusat kehidupan ini (antroposentrisme). Padahal berdasarkan hasil kajiannya terhadap prinsip ajaran Islam, posisi manusia sebagai khalifah di bumi bukanlah cek kosong bagi manusia untuk melampiaskan segala hasratnya terhadap alam. Manusia memang 
diciptakan dengan berbagai kelebihan yang menjadikan dirinya sebagai khalifah, namun posisi itu diberikan Allah SWT kepada manusia dengan berbagai tugas yang harus diembannya (Fata, 2015). Selanjutnya, penelitian yang dilakukan oleh Masruri (2014), "Pelestarian Lingkungan dalam Perspektif Sunnah," artikel ini diterbitkan di jurnal at-Taqaddum. Hasil penelitian ini menyimpulkan bahwa salah satu sunnah Rasulullah Saw. menjelaskan setiap warga berhak untuk mendapatkan mafaat dari suatu sumberdaya alam milik bersama untuk memenuhi kebutuhan-kebutuhan hidupnya sepanjang tidak melanggar, menyalahi, dan menhalangi hak-hak yang sama pada diri orang lain. Penggunaan sumberdaya alam yang langka harus tetap mendapat pengawasan dan perlindungan yang baik. Hal ini, untuk menjaga keberlangsungan kehidupan di dunia dan menjauhkan kerusakan dan bencana yang terjadi karena ulah sebagian manusia (Masruri, 2014). Maulida (2019), “Bencana-bencana Alam pada Umat Terdahulu dan Faktor Penyebabnya dalam Persfektif Al Qur'an: Studi Tafsir Maudhu'i Ayat-Ayat tentang Bencana Alam," At-Tadabur: Jurnal Ilmu Al-Qur'an dan Tafsir. Penelitian ini menjelaskan bahwa bencana alam adalah salah satu ketentuan Allah Swt. yang terjadi di alam semesta (sunnatullah fi al-kaun) dan tidak terlepas dari unsur sebab akibat (kausalitas) sebagai salah satu bukti kekuasaan-Nya. Perbuatan dosa manusialah yang pada akhirnya mendatangkan bencana sebagaimana terjadi bencana besar pada masa umat terdahulu (Asparina \& Farhani, 2020; Maulida, 2019). Muhlis (2008), “Bencana Alam dalam Perspektif al-Qur'an dan Budaya Madura," artikel ini diterbitkan di jurnal Karsa. Dalam penelitian ini, penulis menunjukan bahwa bencana alam sudah sering terjadi di negara Indonesia. Penulis kemudian menjelaskan tentang terjadinya bencana dalam perspektif Al-Qur'an (Muhlis, 2008).

Bencana alam adalah konsekuensi dari kombinasi aktivitas alamibersifat fisik seperti letusan gunung, gempa bumi, tanah longsor- dan aktivitas manusia, dan karena ketidakberdayaan manusia akibat kurang baiknya manajemen dalam menghadapi keadaan darurat, telah menyebabkan kerugian dalam bidang keuangan dan struktural, bahkan kematian (Muhlis, 2008). Selanjutnya, definisi bencana, sebagaimana tertera dalam Bab I Pasal 1 Undang-Undang Nomor 24 Tahun 2007, adalah bencana yang diakibatkan oleh peristiwa atau serangkaian peristiwa yang disebabkan oleh alam, antara lain berupa gempa bumi, tsunami, gunung meletus, banjir, kekeringan, angin topan, dan tanah longsor (Maulida, 2019). Dalam perspektif Islam, musibah adalah sebuah peristiwa yang pasti dialami oleh setiap manusia, walaupun terjadi dalam bentuk, bo bot dan kadar yang berbeda. Hal ini adalah salah satu ketentuan Allah yang pasti terjadi di alam semesta (sunnatullāh fi al-kaun)(Maulida, 2019).

Filsafat perenial adalah nama lain dari filsafat tradisional. Filsafat perennial selalu membicarakan tentang adanya "Yang Suci" atau "Yang 
Satu", sedangkan filsafat modern justru sebaliknya yaitu membersihkan "Yang Suci" dari alam fikiran(Amalia, 2019). Filsafat perennial secara etimologis, berasal dari bahasa Latin yaitu perennis, yang berarti kekal, selama-lamanya selama-lamanya atau abadi. Sehingga Filsafat Perennial dikatakan juga sebagai Filsafat Keabadian (Kuswanjono, 1997). Menyangkut kata "abadi" ini, ada dua macam interpretasi yang berbeda. Pertama, sebagai nama diri (proper name) dari suatu tradisi filsafat tertentu. Kedua, sebagai sifat yang menunjuk pada sistem filsafat yang memiliki keabadian ajaran, apapun namanya. Menurut Huston Smith terdapat dua tradisi besar filsafat yang sangat kontras, yaitu "Filsafat Modern" dan "Filsafat Tradisional". Filsafat tradisional atau yang lebih dikenal dengan filsafat perennial selalu membicarakan tentang adanya "Yang Suci" (The Sacred) atau "Yang Satu" (The One) dalam seluruh manifestasinya, seperti dalam agama, filsafat, sains dan seni. Sedangkan filsafat modern justru sebaliknya membersihkan "Yang Suci" dan "Yang Satu". Mereka tidak hanya memisahkan persoalan spiritualitas dari keduniawian, bahkan ingin menghilangkan sama sekali (Hidayat dan Nafis, 1995). Filsafat perenial dipandang mampu menjelaskan segala kejadian yang bersifat hakiki menyangkut kearifan yang diperlukan dalam menjalankan hidup yang benar yang menjadi hakikat dari seluruh agama dan tradisi-tradisi besar spiritualitas manusia (Kuswanjono, 1997). Menurut Huxley ada tiga konsep dasar filsafat perennial. Pertama, metafisika yang memperlihatkan suatu hakikat kenyataan Ilahi dalam kehidupan dan pikiran. Kedua, psikologi yang memperlihatkan adanya sesuatu dalam roh atau jiwa manusia yang identik dengan kenyataan Ilahi itu. Ketiga, etika yang meletakkan tujuan akhir manusia dalam pengetahuan akan dasar semua yang ada, yang bersifat imanen maupun transenden (Amalia, 2019).

Berdasarkan paparan di atas, rumusan masalah penelitian ini adalah terdapat bencana banjir dan longsor dalam tinjauan filsafat perennial. Atas dasar inilah, maka pertanyaan penelitian ini adalah bagaimana bencana banjir dan longsor dalam tinjauan filsafat perennial atau filsafat keabadian. Di samping itu, tujuan penelitian ini adalah untuk menganalisa terjadinya bencana banjir dan longsor secara filosofis, dalam hal ini tentunya dalam perspektif filsafat perenial.

\section{Metode Penelitian}

Metode penelitian ini menggunakan pendekatan kualitatif. Metode pengumpul data yang digunakan adalah tinjauan literatur yang berkaitan dengan bencana dan filsafat perenial. Hal pertama yang dilakukan penulis adalah mengumpulkan beberapa literatur baik berupa buku, artikel, dan dokumen lainnya Setelah bahan terkumpul, selanjutnya penulis melakukan analisis dokumen dan mendeskripsikannya. 


\section{Hasil dan Pembahasan}

Filsafat tradisional atau filsafat perennial hadir sebagai bentuk kritik atas modernism dan postmodernisme. Filsafat perennial mencoba mengingatkan kembali manusia-manusia modern yang sudah terlampau materialis. Modernism dengan segala bentuk kemajuannya terutama dalam sains dan teknologi, telah membawa pada rusaknya keseimbangan tatanan ciptaan karena telah memisahkan manusia dengan alam (Wora, 2006).

Modernism, yang sering dianggap sebagai puncak keberhasilan karya manusia, justru membawa dampak yang lebih serius, yaitu krisis lingkungan. Ciri kemodernan adalah adanya sikap dominasi atau penguasaan manusia terhadap alam. Hal ini dapat terlihat dari bentuk ekploitasi alam secara besar-besaran yang tidak pernah terjadi sebelumnya.

Manusia modern telah menjadikan alam sebagai objek yang harus dikuasai. Hal ini diakibatkan oleh keyakinan bahwa manusia dianggap sebagai entitas terpisah dari alam. Kemodernan telah membuat manusia angkuh dengan kemampuannya sehingga membuatnya lebih menekankan pada individualitas yang absolut.

Menurut Emanuel Wora (2006), paradigma modern ini dimulai sejak Rene Descaartes ketika memperkenalkan konsepnya yang terkenal hingga hari ini yaitu "cogito ergo sum". Begitupun dengan Francis Bacon dan Isaac Newton yang telah memperkenalkan konsep dasar bagi perkembangan sains modern yang pada akhirnya menjadi pendukung utama kecenderungan individualistic modern. Sebagaimana diktehaui bahwa Descartes dalam teori "cogito ergo sum" telah berupaya untuk memisahkan materi dan pikiran sebagai entitas yang berbeda. (sejarah filsafat).

Melalui teorinya, Descartes meyakinkan manusia tentang independensi pikiran. Pikiran berada di atas materi. Konsep Desartes ini lebih jauhnya telah menimbulkan terjadinya dikotomi antara manusia dan alam. Pemikiran rasionalitas Descartes ini kemudian berkembang lebih radikal dan disambut oleh para saintis setelahnya dengan membangun filsafat dan sains sekuler.

Sains modern tidak lagi menganggap kesakralan alam. Alam dianggap menjadi objek profan yang tak lain adalah objek yang harus dikuasai. Barangkali inilah penyebab utama yang nantinya akan membawa manusia modern kedalam dunia kehampaan yang kering akan prinsipprinsip spiritualitas. Dan memang perkembangan filsafat modern yang materialis telah membawa pada hilangnya realitas transenden, yang sejatinya dalam kacamata filsafat perennial adalah inti dari segala sesuatu (Wora, 2006).

Perkembangan sains modern yang materialis dan individualis pada tahapan selanjutnya telah membawa pada malapetaka yakni krisis lingkungan. Manusia modern, menghadapi krisisnya sendiri yang belum pernah terjadi sebelumnya. Perilaku manusia modern ini mengancam 
kehidupan seluruh planet. Perilaku ini telah menjadi sumber krisis lingkungan yang tak berkesudahan. Manusia modern telah melakukan desakralisasi terhadap kosmos, terutama sekali yang terjadi di Barat yakni perkembangan filsafat rasionalisme dan humanism. Renaisans yang telah memicu terjadinya revolusi ilmiah dan penciptaan ilmu yang fungsinya, menurut Francis Bacon, salah satu pendukung utamanya, adalah untuk mendapatkan kekuasaan atas alam, mendominasi dan memaksanya untuk mengungkapkan rahasianya bukan untuk kemuliaan Tuhan tetapi untuk kepentingan untuk mendapatkan kekuatan dan kekayaan duniawi (Seyyed Hossein Nasr, 1988).

Dominasi terhadap alam yang semakin meningkat dan apa yang disebut kemajuan yang seharusnya sejalan dengan ekonominya, banyak yang menyadari dalam hati mereka bahwa kastil yang mereka bangun berada di atas pasir dan bahwa ada ketidakseimbangan antara manusia dan alam yang mengancam kemenangan nyata semua manusia atas alam. Dominasi terhadap alam oleh manusia modern telah membawa pada konseuensi desakralisasi alam. Hal ini tentunya bertolak belakang dengan paradigma filsafat perennial yang justru menganggap alam sebagai bagian tak terpisahkan dari manusia. Menurut Huston Smith filsafat tradisional atau yang lebih dikenal dengan filsafat perennial selalu membicarakan tentang adanya "Yang Suci" (The Sacred) atau "Yang Satu" (The One) dalam seluruh manifestasinya, seperti dalam agama, filsafat, sains dan seni. Sedangkan filsafat modern justru sebaliknya membersihkan "Yang Suci" dan "Yang Satu". Mereka tidak hanya memisahkan persoalan spiritualitas dari keduniawian, bahkan ingin menghilangkannya dari semua objek alam (Hidayat dan Nafis, 1995).

Selain itu, alam telah dianggap sebagai sesuatu untuk digunakan dan dinikmati semaksimal mungkin. Menurut Nasr, manusia modern telah kehilangan tanggung jawabnya terhadap alam. Nasr menganalogikan bahwa manusia modern layaknya seperti pelacur - untuk mendapatkan keuntungan tanpa rasa kewajiban dan tanggung jawab terhadapnya (Seyyed Hossein Nasr, 1988).

Pada akhirnya, keterlanjuran dominasi alam oleh manusia modern telah menyebabkan masalah populasi yang berlebihan, kurangnya 'ruang bernafas', koagulasi dan kemacetan kehidupan kota, habisnya segala jenis sumber daya alam, kerusakan keindahan alam, perusakan lingkungan hidup melalui mesin dan produknya, peningkatan abnormal penyakit mental dan seribu satu kesulitan lainnya yang beberapa di antaranya tampak sama sekali tidak dapat diatasi (Seyyed Hossein Nasr, 1988).

Hampir terdapat ketidakseimbangan total antara manusia modern dan alam seperti yang dibuktikan oleh hampir setiap ekspresi peradaban modern yang berusaha menawarkan tantangan kepada alam daripada bekerja sama dengannya. Bahwa keharmonisan antara manusia dan alam 
telah hancur adalah fakta yang diakui kebanyakan orang. Tetapi tidak semua orang menyadari bahwa ketidakseimbangan ini disebabkan oleh rusaknya keharmonisan antara manusia dan Tuhan. Ilmu-ilmu alam modern muncul, substansi kosmos pertama-tama harus dikosongkan dari karakter sakralnya dan menjadi profan.

\section{Kesimpulan}

Hasil penelitian ini menyimpulkan bahwa berbagai fenomena bencana alam seperti banjir dan tanah longsor yang terjadi di tengahtengah kehidupan manusia bisa ditinjau dari sudut pandang filsafat perenial. Dalam filsafat perenial, dalam alam ini tersimpan sesuatu yang suci dan sakral. Alam bukan objek yang bisa diekploitasi secara serampangan oleh manusia. Dalam filsafat perenial, manusia dan alam memiliki keterhubungan yang erat. Oleh sebab itu, manusia harus menjaga keseimbangan dengan alam agar terjadi harmoni. Namun sayangnya, manusia modern dengan sains dan teknologinya telah mencabut kesakralan alam dan menganggap alam sebagai objek yang harus dikuasai. Konsekuensinya, alam menjadi rusak dan hilangnya keseimbangan tatanan alam hingga akhirnya memunculkan berbagai krisis lingkungan. Penelitian ini diharapkan bermanfaat untuk ruang lingkup akademisi agar menjadi renungan dan kajian bersama tentang pentingnya membangun harmoni antara alam dan manusia dengan meninjau kembali kesadaran akan pentingnya kajian filsafat perenial. Meskipun demikian, bagi penulis, kajian ini masih kurang komprehensif terutama dalam pengambilan sumber dokumen. Selain itu, tulisan ini juga hanya fokus pada dua fenomena. Oleh sebab itu, kiranya tulisan ini bisa menjadi pendorong bagi peneliti filsafat untuk menindaklanjuti kajian yang lebih holistik tentang berbagai fenomena kerusakan lingkungan dalam perspektif filsafat. Penelitian ini merekomendasikan pentingnya menjaga alam. Disamping itu, pentingnya meninjau dan melucuti kembali sains modern yang telah mematikan metafisika perenial yang memperlihatkan suatu hakikat kenyataan Ilahi dalam kehidupan dan pikiran.

\section{Referensi}

Amallia, S. (2019). Hakekat Agama Dalam Perspektif Filsafat Perenial. Indonesian Journal of Islamic Theology and Philosophy, 1(1), 1-18. https:/ / doi.org/10.24042/ijitp.v1i1.3903

Asparina, A., \& Farhani, K. R. S. (2020). Mitologi “Bencana adalah Azab” dalam Meme Media Sosial. Khazanah Theologia, 2(3), 164-177. https:/ / doi.org/10.15575/kt.v2i3.9213

Cindy Mutia Annur. (2020, September). Intensitas Bencana Banjir di Indonesia Selama 10 Tahun Terakhir. Https://Databoks.Katadata.Co.Id/.

Fata, A. K. (2015). Teologi Lingkungan Hidup Dalam Perspektif Islam. 
ULUL ALBAB Jurnal Studi Islam, 15(2), 131. https:/ / doi.org/10.18860/ua.v15i2.2666

Komarudin Hidayat dan Mohammad Wahyuni Nafis. (1995). Agama Masa Depan Perspektif Filsafat Perennial. Paramadina.

Kuswanjono, A. (1997). Filsafat Perennial dan Rekonstruksi Pemahaman Keberagamaan. Jurnal Filsafat Edisi Khusus Agustus 1997, 96-108.

Masruri, U. N. (2014). Pelestarian Lingkungan dalam Perspektif Sunnah. At-Taqaddum, 6(2), 411-428.

Maulida, A. (2019). Bencana-bencana Alam pada Umat Terdahulu dan Faktor Penyebabnya dalam Persfektif Al Qur'an: Studi Tafsir Maudhu'i Ayat-Ayat tentang Bencana Alam. At Tadabur:Jurnal Ilmu Al Qur'an Dan Tafsir, IV(02), 130-155. https:/ / doi.org/10.30868/at.v4i02.596

Muhlis, A. (2008). Bencana alam dalam perspektif al-qur'an dan budaya madura. Karsa, XIV(2), 175-186.

Saptoyo, R. D. A. (2021). Banjir di Indonesia, Benarkah karena Curah Hujan dan Cuaca Ekstrem? Kompas.

Seyyed Hossein Nasr. (1988). MAN AND NATURE The Spiritual Crisis of Modern Man SEYYED. Unwin Paperbacks.

Wora, E. (2006). Perenialisme: Kritik atas Modernisme dan Postmodernisme. Kanisius. 